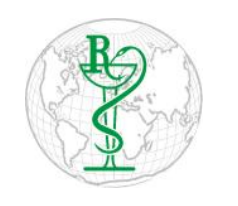

INDO GLOBAL JOURNAL OF

PHARMACEUTICAL SCIENCES

ISSN 2249- 1023

\title{
Microbicidal Potentialities of Essential Oil from Pogostemon benghalensis (Burm.F.) Kuntze. and P. cablin (Blanco) Benth.
}

\author{
Pradeep D.P. ${ }^{* 1}$, Manoj G.S. ${ }^{1}$, Murugan K ${ }^{2}$ \\ ${ }^{1}$ Department of Botany, M.G. College, Kesavadasapuram, Trivandrum, Kerala, India \\ ${ }^{2}$ RUSA, Department of Higher Education, Govt. of Kerala, India
}

Address for Correspondence: Pradeep D.P., prempradeep358@gmail.com

\begin{abstract}
Received:
04.07.2019

Accepted:

27.04.2020

Published:

24.11.2020

Keywords

Pogostemon

benghalensis;

GC-MS;

Escherichia coli;

MIC; Potassium

ions.
\end{abstract}

\begin{abstract}
The essential oils from Pogostemon benghalensis and P. cablin were isolated and the major compounds were identified by GC-MS technique. The antimicrobial potentials of essential oils from Pogostemon benghalensis and $P$. cablin were tested against clinically important microorganisms. Gram negative bacteria includes Escherichia coli (ATCC 25922), Salmonella typhimurium (ATCC 13311), Pseudomonas aeruginosa (ATCC 85327) and Klebsiella pneumoniae (ATCC10031) and Gram positive bacteria include Staphylococcus aureus (ATCC 25923), Staphylococcus epidermidis (ATCC 12228), Bacillus subtilis (DSMZ 1971), Bacillus cereus (ATCC 11778) were used for the present study. Also Aspergillus niger (ATCC 16404) and Candida albicans (ATCC 10231) were used as the fungal strains. The minimum inhibitory concentration (MIC), minimum killing concentration (MKC), leakage of potassium ions, release of $260 \mathrm{~nm}$ absorbing materials was analysed. 41 and 36 fractions were identified from the essential oils of Pogostemon benghalensis and $P$. cablin respectively. The result indicated that oils have significant antimicrobial properties against the selected strains of microorganisms. In conclusion the essential oils of Pogostemon benghalensis and P. cablin can be used as a natural source for antimicrobial agents and could be used for application in pharmaceutical and food industries. () 2020 iGlobal Research and Publishing Foundation. All rights reserved.
\end{abstract}

Cite this article as: Pradeep, D.P.; Manoj, G.S.; Murugan, K. Microbicidal potentialities of essential oil from Pogostemon benghalensis (Burm.F.) Kuntze. and P. cablin (Blanco) Benth. Indo Global J. Pharm. Sci., 2020; 10(3): 41-47. DOI: http://doi.org/10.35652/IGJPS.2020.10305 .

\section{INTRODUCTION}

Aromatic plant species and their essential oils (Eos) have been used from the beginning of human civilization for various purposes. These oils are mainly used for flavouring the food and beverage [1]. The Eos is commonly in liquid form, clear and light coloured complex and volatile. The Eos are characterised by its strong odour among the secondary metabolites [2]. Eos is ubiquitous in buds, flower, leaves, stem, seed, root or trichomes of aromatic plants [3]. Plants have been traditionally used as a folk medicine to extend the shelf life of foods, to inhibit the action of microorganism, to treat various diseases. The Eos is used from the prehistoric times as antimicrobial, antiseptic and for other therapeutic purposes by the indigenous peoples [4]. From the study of the WHO, approximately $80 \%$ of the world population, mostly in developing countries, still relies on herbals and their extracts for primary health needs [5]. The Eos and other secondary metabolites present in the plants are responsible for its medicinal properties. Eos is proven for its antimicrobial, antiviral, and antioxidants activities [6]. Also, Eos are employed as an additive in antibacterial agents and proved with high efficacy to be safe [7]. Antibiotics are commonly and widely used for many bacterial and fungal infections. From the time period of the invention of antibiotics these chemotherapeutics are used to eradicate many diseases. However, the uncontrolled and over dosage of these antibiotics leads to the emergence and dissemination of multi drug resistant strains in several microorganisms [8]. Such multi drug resistant strains of Escherichia coli and Klebsiella pneumoniae had isolated from community acquired infections [9]. Many pathogenic microorganisms which infect human being have become a primary constraint in terms of economic 


\section{Indo Global Journal of Pharmaceutical Sciences, 2020; 10(3): 41-47}

and socio-economic development in many developing countries of the world [10].

Pogostemon benghalensis and Pogostemon cablin belong to Lamiaceae. $P$. cablin is native to tropical regions of Asia and is now extensively cultivated in China, Indonesia, India, Malaysia, Mauritius, Philippines, Thailand, Vietnam, and West Africa. In India the plant is introduced on 1942 and showed suitability to cultivate along the tropical humid South Indian conditions [11]. However, Pogostemon benghalensis is an underexploited plant restricted to high altitude areas. GuribFakim [4] and Valiakos et al., [5] reported that the species were used by the native people of Kerala, India for curing many skin prone disorders and also as antiseptic agents. No scientific reports are documented regarding the antimicrobial activities of $P$. benghalensis and Pogostemon cablin used by the native people. Further, due to the adverse effect of synthetic antibiotics, new or novel plant based antimicrobial agents are to be explored urgently. Therefore the medicinal properties of herbal plants and their products are nowadays being thoroughly studied, revised in an effort to complement or replace the existing synthetic chemical substances used in the modern food and drug industries. In this scenario, the purpose of the present study is to isolate, fractionate the components of essential oils from Pogostemon benghalensis and $P$. cablin and examine their microbicidal potentialities.

\section{MATERIALS AND METHOD}

\section{Plant Material}

Fresh leaves and twigs of Pogostemon benghalensis and P.cablin used in the present study were collected from the natural habitats of Munnar Hills of Idukki district, Kerala, India on July 2019. The collected species were identified using flora and were authenticated at the Herbarium of Jawaharlal Nehru Tropical Botanic Garden and Research Institute (JNTBGRI), Palode, Trivandrum, Kerala, India. The voucher specimens were numbered (MGH 1456 and 1457 for Pogostemon benghalensis and P.cablin respectively) and kept in the herbarium of the Department of Botany, M.G. College, Trivandrum, Kerala, India. The collected plants were washed thoroughly with running tap water, air-dried and ground to a coarse powder, and stored in air tight bottles at $4{ }^{\circ} \mathrm{C}$.

\section{Extraction and analysis by GC/MS}

Hydro-distillation of fresh powders of the selected Pogostemon species was carried out using a Clevenger-type apparatus. GC-MS analysis was done out using HewlettPackard 6890 gas chromatography (Agilent Technologies, USA). $1 \mu \mathrm{l}$ of essential oils from each species was injected into the machine fitted with an HP-5 (5\% phenyl methylpolysiloxane, $30 \mathrm{~m} 0.32 \mathrm{~mm}$ i.d., and $0.25 \mu \mathrm{m}$ film thicknesses) capillary column coupled with a model 5973 mass detector. GC- MS operation conditions were injector temperature: $220^{\circ} \mathrm{C}$; transfer line temperature: $240^{\circ} \mathrm{C}$; oven temperature programme: $60-246^{\circ} \mathrm{C}\left(3^{\circ} \mathrm{C} / \mathrm{min}\right)$; carrier gas: helium $(1.4 \mathrm{ml} / \mathrm{min})$; detector temperature: $250^{\circ} \mathrm{C}$; mass spectra, electron impact (EI+) mode, $70 \mathrm{eV}$; ion source temperature: $240^{\circ} \mathrm{C}$.

\section{Microbial strains}

The antimicrobial activity of the essential oils was determined by both Gram negative and Gram positive strains. Also two fungal strains were used to study the microbicidal activity of Eos. Gram negative bacteria includes Escherichia coli (ATCC 25922), Salmonella typhimurium (ATCC 13311), Pseudomonas aeruginosa (ATCC 85327) and Klebsiella pneumoniae (ATCC10031) and Gram positive bacteria include Staphylococcus aureus (ATCC 25923), Staphylococcus epidermidis (ATCC 12228), Bacillus subtilis (DSMZ 1971), Bacillus cereus (ATCC 11778) were used for the present study. While Aspergillus niger (ATCC 16404) and Candida albicans (ATCC 10231) were used as the fungal strains.

\section{Microbicidal activity}

The disk diffusion method was used to study the antimicrobial activity of Eos [12]. The medium used for bacterial culture was Mueller-Hinton Agar and Sabouraud Dextrose Agar for the fungi strains. $0.1 \mathrm{ml}$ suspension containing about $108 \mathrm{CFU} / \mathrm{ml}$ test microorganism is uniformly spread on the culture medium. Whatman No.1 filter paper was used for making sterile $6 \mathrm{~mm}$ disk. Each sterile disk containing $1 \mathrm{mg} / \mathrm{ml}$ of Eos was placed in a microbial lawn. Inoculated plates with disk were incubated at $37^{\circ} \mathrm{C}$ for $24 \mathrm{~h}$ for the bacteria and at 30 ${ }^{\circ} \mathrm{C}$ for $48 \mathrm{~h}$ for the fungi. After incubation period the inhibition zone was measured in each disk in the culture plate and the data was noted in $\mathrm{mm}$. Ciprofloxacin and Chloramphenicol were used as standard against bacterial and fungal strains respectively. The experiments were conducted in triplicate.

\section{Minimum Inhibitory Concentration (MIC) and Minimum Killing Concentration (MKC)}

The antimicrobial activity of essential oils was determined by Minimum inhibitory concentration (MIC) as per the protocol of Bajpai et al., [13]. Briefly, the suspensions of bacterial strains prepared from overnight broth cultures, were adjusted to the required microbial density (about $107 \mathrm{CFU} / \mathrm{ml}$ ). Eos was dissolved in $20 \%$ of anhydrous ethanol, then twofold serial dilutions were made in a concentration ranging from 0.125 to $32 \mathrm{mg} / \mathrm{ml}$ in $10 \mathrm{ml}$ sterile test tubes. A $50 \mathrm{ml}$ 


\section{Indo Global Journal of Pharmaceutical Sciences, 2020; 10(3): 41-47}

suspension of each strain was added into the tube. The tube containing only broth and the bacterial strain was the negative control. The minimal inhibitory concentration (MIC) was defined as the lowest concentration of oil inhibiting the visible growth of bacteria. Positive and negative control was incubated under the same condition. To determine minimum killing concentration (MKC), $100 \mu \mathrm{l}$ of the culture from each well of the micro-broth assay was sub-cultured on $\mathrm{MH}$ agar plates after 24 hours of the incubation. MH plates were further incubated for 24 hours. Minimal killing concentration (MKC) was defined as the lowest concentration of oil or active compound in the test tube showing no growth in sub-culture.

\section{Potassium ions efflux assay}

The concentration of free potassium ions leaching from bacterial and fungal suspensions was measured as per the method of Bajpai et al., [13] to evaluate the permeability of cell membrane. The microorganisms were treated with Eos at MIC concentration in sterile peptone water and the free potassium ions efflux were measured at 30, 60, 90 and 120 min intervals by photometric method using calcium/potassium kit. A positive control was tested without Eos. Results were expressed as amount of extracellular free potassium $(\mathrm{mmol} / \mathrm{l})$ in the growth media in each interval of incubation.

\section{Measurement of release of 260-nm absorbing cellular}

The release of 260-nm-absorbing materials from bacterial and fungal strains was carried out at $260 \mathrm{~nm}$ using a 96-wellplate ELISA reader [14]. Cells from the $100 \mathrm{ml}$ bacterial suspension were collected by centrifuging at 5,000 $\mathrm{x} g$ for 15 min, washed thrice with 0.1 M PBS ( $\mathrm{pH} 7.4$ ), and resuspended in PBS (0.1 M, pH 7.4). The $100 \mathrm{ml}$ of cell suspensions was incubated at $37^{\circ} \mathrm{C}$ under agitation in an environmental incubator shaker for $4 \mathrm{~h}$ in the presence of Eos (control, $1 \mathrm{x}$ MIC). Then, the suspensions were centrifuged at $6,000 \times g$ for 5 min. The supernatants were diluted with PBS $(0.1 \mathrm{M}, \mathrm{pH}$ 7.4). Then the absorption at $260 \mathrm{~nm}$ of supernatants was measured using a 96-Well Plate Reader per 4h. Results were expressed in terms of optical density of 260-nm absorbing materials.

\section{Statistical Analysis}

$t$ - test and standard deviation were calculated applying Systat software to evaluate whether the differences between the means were statistically significant.

\section{RESULTS AND DISCUSSION}

\section{GC-MS Analysis}

The GC-MS analysis identified 41 and 36 volatile compounds from the Eos of $P$. benghalensis and $P$. Cablin respectively. $\alpha$ Cadinol $(35.78 \%)$ and patchouli alcohol $(34.85 \%)$ were the major components in these oils. The predominant components of $P$. benghalensis were 1,8 cineole $(7.14 \%)$, aromadendrene (4.16\%), p-cymene (1.6\%), bornylacetae (2.15\%), longicyclene $(2.74 \%), \quad \beta$-elemene $(1.56 \%)$, longifolene $(1.18 \%), \alpha$-caryophyllene (1.08\%), $\beta$-caryophyllene $(1.14 \%)$, trans- $\beta$-farnesene $(1.56 \%), \alpha$-patchoulene $(2.39 \%)$, gurjunene (2.86\%), valencene (2.21\%), epi-cubedol (1.03\%), bicyclogermacrene $(2.78 \%)$, trans- $\beta$-guaiene $(1.26 \%), \alpha$ bisabolene $(1.16 \%)$, $d$-cadinene $(2.45 \%)$, elemol $(1.01 \%)$, spathulenol(1.16\%), caryophyllene oxide (1.15\%), guaiol (1.79\%), isolongifol (1.20\%), cubenol-1-epi (1.56\%), $\alpha$ murolol (1.45\%), bulsenol (1.51\%) and cadalene- 8,9-epoxide $(2.95 \%)$.

\begin{tabular}{|c|c|c|c|c|c|c|c|}
\hline \multirow{2}{*}{ SI No. } & Strains & \multicolumn{3}{|c|}{ P. benghalensis } & \multicolumn{3}{c|}{ P. cablin } \\
\cline { 3 - 7 } & & $\begin{array}{c}\text { DI } \\
(\mathbf{m m})\end{array}$ & $\begin{array}{c}\text { MIC } \\
(\mathbf{m g} / \mathbf{m l})\end{array}$ & $\begin{array}{c}\mathbf{M K C} \\
(\mathbf{m g} / \mathbf{m l})\end{array}$ & $\begin{array}{c}\text { DI } \\
(\mathbf{m m})\end{array}$ & $\begin{array}{c}\text { MIC } \\
(\mathbf{m g} / \mathbf{m l})\end{array}$ & $\begin{array}{c}\text { MKC } \\
(\mathbf{m g} / \mathbf{m l})\end{array}$ \\
\hline 1 & S. aureus (+) & 12.4 & 0.375 & 0.842 & 10.7 & 0.514 & 1.083 \\
\hline 2 & S. epidermidis (+) & 6.3 & 1.314 & 2.048 & 5.4 & 1.568 & 2.316 \\
\hline 3 & B. subtilis (+) & 13.8 & 0.289 & 0.744 & 8.6 & 0.643 & 1.385 \\
\hline 4 & B. cereus (+) & 12.6 & 0.315 & 0.823 & 10.5 & 0.504 & 1.213 \\
\hline 5 & S. typhimurium (-) & 5.6 & 1.429 & 1.983 & 6.2 & 1.341 & 1.845 \\
\hline 6 & E. coli (-) & 4.8 & 1.623 & 2.814 & 4.5 & 1.981 & 3.086 \\
\hline 7 & P. aeruginosa (-) & 9.88 & 0.568 & 1.214 & 11.6 & 0.416 & 1.018 \\
\hline 8 & K. pneumoniae (-) & 4.7 & 1.892 & 3.084 & 4.9 & 1.961 & 2.783 \\
\hline 9 & A. niger & 13.5 & 0.362 & 0.941 & 12.3 & 0.462 & 0.741 \\
\hline 10 & C. albicans & 14.6 & 0.293 & 0.786 & 10.4 & 0.491 & 0.953 \\
\hline
\end{tabular}

Table 1 .Microbicidal activity of the essential oils of $P$. benghalensis and $P$. cablin in terms of Diameter of inhibition zone $(\mathrm{mm})$, minimal inhibition and killing concentration (MIC \& MKC) $(\mathrm{mg} / \mathrm{ml})$. 
Indo Global Journal of Pharmaceutical Sciences, 2020; 10(3): 41-47

In addition to patchouli alcohol, the essential oils of $P$. cablin contained $\alpha$-pinene $(2.38 \%), \quad 1,8$ cineole $(4.21 \%), \quad \beta$ patchoulene $(8.45 \%), \quad \alpha$-caryophyllene $\quad(1.02 \%), \quad \beta$ caryophyllene $(3.21 \%)$, $\alpha$-guaiene $(5.73 \%)$, aromadendrene (2.78\%), $\alpha$-patchoulene $(6.18 \%)$, alloaromadendre $(2.17 \%)$, seychellene $(1.84 \%)$, cis- $\beta$-guaiene $(1.37 \%), \alpha$-selinene (4.36\%), trans- $\beta$-guaiene (1.03\%), germacrene A $(5.48 \%), \alpha$ bulnesene $(1.42 \%)$, globulol $(2.37 \%)$ and guaiol $(2.47 \%)$ as the major components. This is the first report of GC-MS of essential oils of $P$. cablin.

\section{Microbicidal activity}

Many pathogens which cause various infections exhibit drug resistance by creating tolerance against the antibiotics. Thus, there is a need for the discovery of novel natural substances especially from plant origin. The essential oils of $P$ benghalensis and $P$. cablin were tested against four Grampositive, four Gram-negative bacteria and two fungal species. The antimicrobial activity of the essential oils was preliminary analysed by disc diffusion method. $4.5 \mathrm{~mm}$ to $11.6 \mathrm{~mm}$ zone of inhibition was resulted against the bacterial strains and 10.4 $\mathrm{mm}$ to $12.3 \mathrm{~mm}$ was obtained against the fungal strains. The most sensitive bacterial strains were $B$. subtilis and $P$. aeruginosa for $P$. benghalensis and for $P$. cablin respectively with inhibition zones of $13.8 \mathrm{~mm}$ and $11.6 \mathrm{~mm}$ respectively. Both the fungal strains were sensitive to Eos showed $12.3 \mathrm{~mm}$ to $10.4 \mathrm{~mm}$ inhibition zone. While least antimicrobial activity was noted against $K$. pneumoniae and $E$. coli with inhibition zone of $4.9 \mathrm{~mm}$ and $4.5 \mathrm{~mm}$ respectively.

The efficacy of the Eos on selected bacterial strains was analyzed by measuring the MIC and MKC (Table 1). The MICs of Eos from Pogostemon species showed varied values against the different bacterial strains. Bacterial cells treated with $P$. benghalensis displayed significant MIC values against Bacillus subtilis followed by B. cereus $S$. aureus i.e., 0.289, 0.315 and $0.375 \mathrm{mg} / \mathrm{ml}$ respectively. Meanwhile, $P$. cablin showed remarkable MIC values against $P$. aeruginosa, $B$. cereus and $S$. aureus $(0.416,0.504,0.524 \mathrm{mg} / \mathrm{ml}$ respectively).

Similarly, the MKC activity of essential oils from $P$. benghalensis against Bacillus subtilis, B. cereus $S$. aureus were $0.744,0.823$ and $0.842 \mathrm{mg} / \mathrm{ml}$ respectively. MKC of Eos from $P$. cablin on $P$. aeruginosa, B. cereus and $S$. aureus were $1.018,1.083$ and $1.213 \mathrm{mg} / \mathrm{ml}$ respectively. Thus, MIC and MKC values suggest that the essential oils has moderate to high inhibitory activity against the tested bacteria. The essential oils showed optimal antimicrobial activity against the tested microorganisms. However, Eos of $P$. benghalensis showed poor MKC values against $K$. pneumoniae $(1.892$ $\mathrm{mg} / \mathrm{ml})$ and $E$. coli $(1.623 \mathrm{mg} / \mathrm{ml})$ suggesting the most resistant microbes. Similar values for $K$. pneumoniae and $E$. coli from the Eos of $P$. cablin were 2.783 and $3.086 \mathrm{mg} / \mathrm{ml}$.

Interestingly, the fungal strains displayed significant fungicidal activity against the essential oils from the Pogostemon species i.e., MIC for A. niger and C. albicans from $P$. benghalensis were 0.362 , and $0.293 \mathrm{mg} / \mathrm{ml}$. The respective MKC values were 0.941 and $0.786 \mathrm{mg} / \mathrm{ml}$ respectively. P.cablin also displayed a more or less similar trend (Table 1). The remarkable MIC and MKC values against the selected Gram positive, Gram negative bacteria and the fungal strains indicates the potent microbicidal activity of the essential oils of the species.

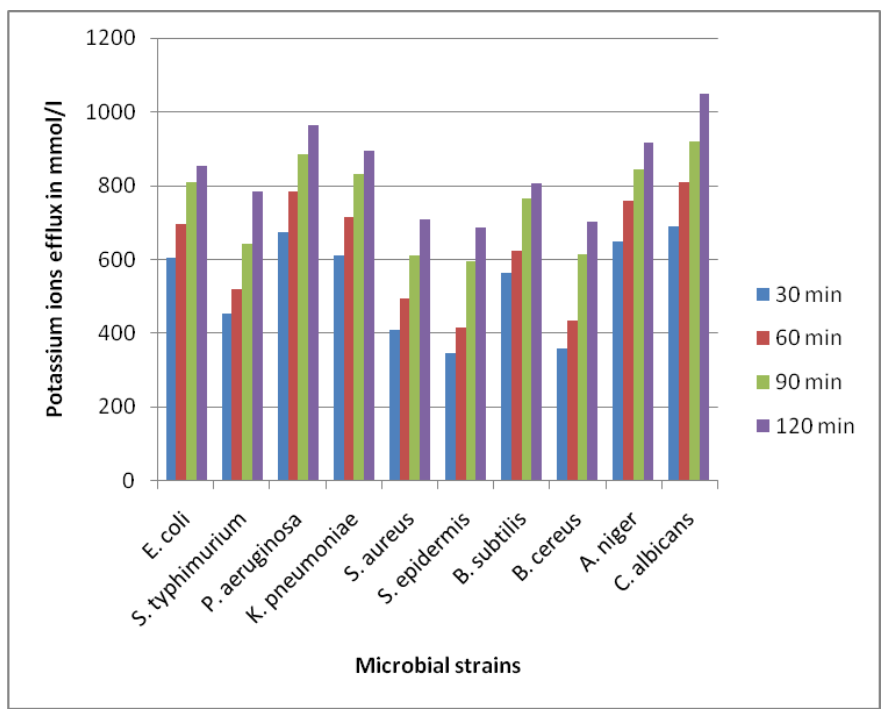

Figure 1. Potassium ions efflux (mmol/l) after 30, 60, 90, 120 min intervals, treated with of Eos from $P$. benghalensis at MIC concentration among selected microbial strains

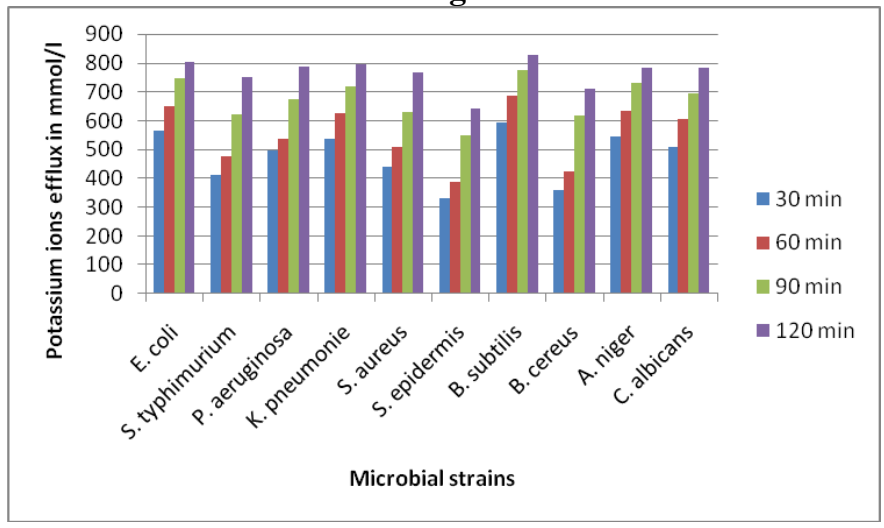

Figure 2. Potassium ions efflux (mmol/l) after 30, 60, 90, 120 min intervals, treated with of Eos from $P$. cablin at MIC concentration among selected microbial strains

\section{Measurement of potassium ion leakage}

The mode of microbicidal action of Eos from $P$. benghalensis and $P$. cablin was further substantiated by the release of potassium ions from the treated cells (Figure $1 \& 2$ ). There is 


\section{Indo Global Journal of Pharmaceutical Sciences, 2020; 10(3): 41-47}

a concentration dependant efflux of potassium ions was noticed on the culture media against the time. However, there was no leakage of potassium ions was observed in the control bacterial cells during the entire period of study i.e., $<10$ $\mathrm{mmol} / \mathrm{l}$. For example, $\mathrm{K}+$ leakage for $E$. coli by Eos from $P$. benghalensis was $855 \mathrm{mmol} / \mathrm{l}$ and the value for $B$. subtilis was $826 \mathrm{mmol} / \mathrm{l}$ by $P$. cablin. Similarly, C. albicans showed a leakage of 1050 and $781 \mathrm{mmol} / \mathrm{l}$ respectively against Eos from $P$. benghalensis and $P$. cablin. The obtained data corroborates with the diameter of zone of inhibition displayed by the respective strains.

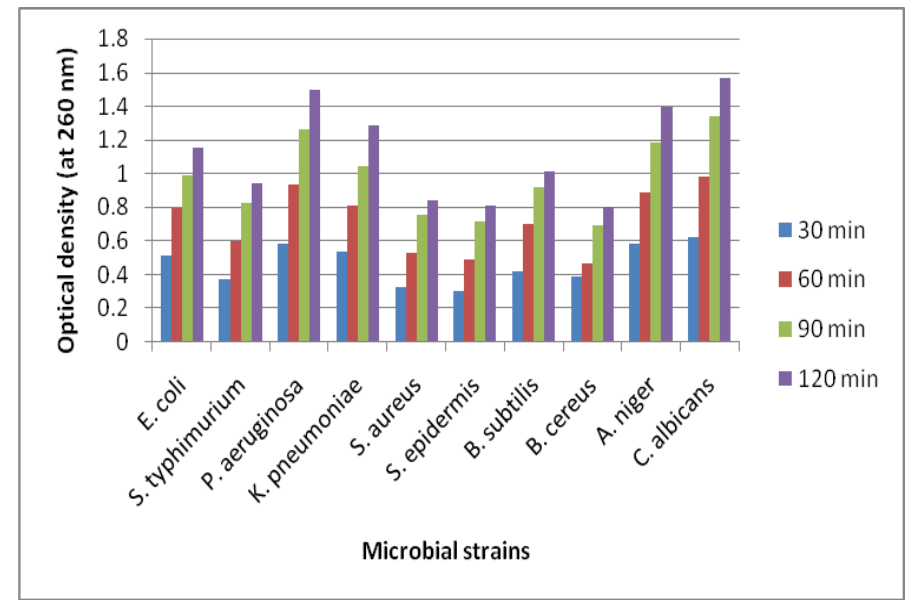

Figure 3. Effect of the P. benghalensis Eos on the release rate of $260-\mathrm{nm}$ absorbing material from selected microbial strains at 30, 60, 90, 120 min time intervals

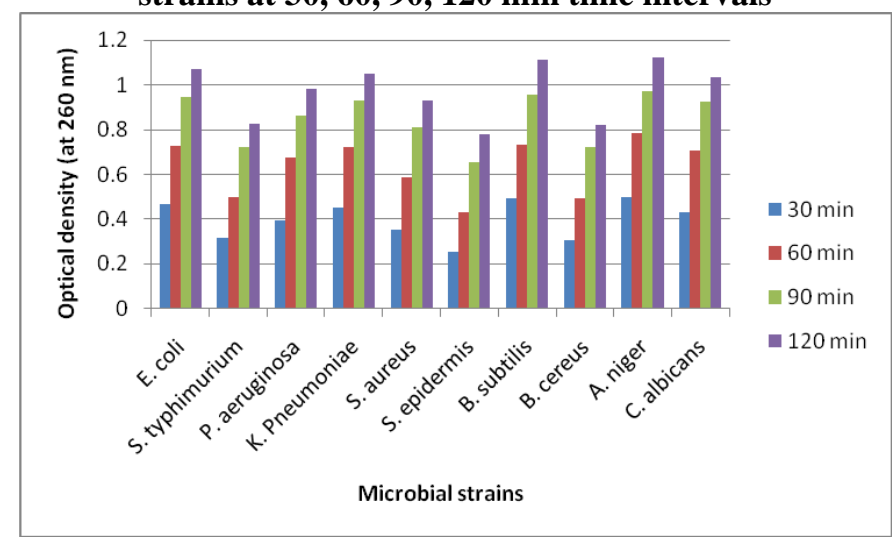

Figure 4. Effect of the P. cablin Eos on the release rate of 260-nm absorbing material from selected microbial strains at 30, 60, 90, 120 min time intervals

\section{Measurement of $260 \mathrm{~nm}$ materials}

Further, the antimicrobial mode of action of Eos was visualized by the confirmation on the leakage of $260 \mathrm{~nm}$ absorbing materials from the treated cells at MIC value. In this experiment the microbial cells treated with Eos showed a rapid loss of $260 \mathrm{~nm}$ absorbing materials. The optical density at 260 $\mathrm{nm}$ of the culture filtrates of microorganism exposed to Eos from $P$. benghalensis and $P$. cablin revealed an increasing release of $260 \mathrm{~nm}$ absorbing materials with respect to exposure time (Figure $3 \& \mathbf{4}$ ). There are no changes in the optical density of control cells of the tested pathogens were observed during the study. 2-fold increase was observed in the optical density of the microbial cell culture filtrates treated with Eos after $120 \mathrm{~min}$ of treatment. OD displayed by the $P$. aeruginosa and $B$. subtilis exposed to Eos from $P$. benghalensis and $P$. cablin were 1.498 and 1.113 respectively. The OD revealed by $C$. albicans was 1.563 and 1.036 respectively for the Eos.

Natural herbal products contain a pool of secondary metabolites and are widely used in the pharmaceutical industry for their remarkable structural diversity and range of pharmacological activities. The understanding of the mode of antimicrobial potential of herbal extracts is important in the course of optimal utilization of the products as natural antimicrobial drugs. Increasing antibiotic resistance and the scarcity of novel antimicrobials has long been acknowledged. The major challenge in global health care is the need for novel, effective and affordable drugs to treat pathogen infections, especially in developing countries of the world, where up to one-half of deaths are due to infectious diseases [15]. The essential oils of Pogostemon species showed several biological properties such as aromatherapy, antibacterial, antifungal, antioxidant, insecticide, and insect repellent activities [16].

Sartorratto et al., [17] expressed the antimicrobial activity of Eos from aromatic plants used in Brazil by its MIC value viz., significant microbicidal activity was found with MIC value up to $500 \mu \mathrm{g} / \mathrm{ml}$, moderate MIC potentials at 600 to $1500 \mu \mathrm{g} / \mathrm{ml}$ and weak for MICs above $1500 \mu \mathrm{g} / \mathrm{ml}$. The Gram-negative species are commonly less sensitive to the essential oils because of its outer resistant membrane that serves as an effective barrier [18]. Betoni et al., [19] also reported that Gram positive species are more sensitive to natural products than the Gram-negative bacteria. The present study revealed that Gram negative bacteria such as Escherichia coli, Salmonella typhimurium, Pseudomonas aeruginosa and Klebsiella pneumoniae were most resistant to the essential oils from Pogostemon species as compared to the Gram positive bacteria Staphylococcus aureus, Bacillus subtilis and B. cereus.

Approximately $50 \%$ of the Candida species population forms the part of the oral microbiota. However, under certain conditions, they may behave as opportunistic pathogens i.e., producing infections ranging from superficial mucosal lesions to serious and invasive systemic dissemination, potentially fatal against immune compromised patients. C. albicans, 


\section{Indo Global Journal of Pharmaceutical Sciences, 2020; 10(3): 41-47}

followed by species $C$. glabrata, $C$. tropicalis, $C$. parapsilosis and $C$. krusei were the most isolated infectious species reported globally [20].The results found in this study substantiates the data revealed by the Das et al., [11] and Wang et al., [21] related with the antifungal potential of Pogostemon species against Candida albicans (0.293 and $0.491 \mathrm{mg} / \mathrm{ml}$ MIC values; 0.786 and $0.953 \mathrm{mg} / \mathrm{ml})$. Generally, the MIC and MKC values $<1 \mathrm{mg} / \mathrm{ml}$ is acceptable as antimicrobial agents [12].

In the present study, the membrane permeability parameters such as leakage of potassium ions, loss of $260 \mathrm{~nm}$ absorbing materials were also monitored. Based on the data the mode of action of Eos was via the damage of cell membrane integrity. Previously, studies of Bajpai et al., [13] also reported that the essential oils had significant effect on the release of potassium ions from the bacterial cells denoting its mode of action by depolarizing the cell membrane.

Hydrophobicity of bactericidal fractions of Eos enables them to split the lipid portion in the cell membranes and other major cell organelles resulted into structural disturbance, changing their functions and rendering them permeable. In addition, the active fractions can lead to disrupt the synthesis of DNA, RNA, protein, or carbohydrates, and then cause cell death [20]. Considering the array of different groups of chemical fractions of Eos from the Pogostemon species likely attributes to more than one specific mode targets in the cell. Therefore, the permeability and integrity of cell membrane in terms of $\mathrm{K}+$ efflux and release of 260 absorbing materials were chosen to determine the mode of action of Eos against the pathogenic strains.

The cell membrane of the bacteria provides the permeability barrier to the passage of ions, which are needed electrolytes to facilitate plasma membrane functions, maintain proper enzyme activity and keep the metabolism normal [21]. Burt [22] documented that Eos form membrane channels via pushing the fatty acid chains of the phospholipids, allowing ions to leach the cytoplasm. Increase in the leakage of $\mathrm{K}+$ suggests the derailment of the permeability barrier. The results in this study showed that the relative $\mathrm{K}+$ efflux increased rapidly with the treatment period of Eos, which meant that the permeability of the membrane would increase accordingly, then cause the leakage of $\mathrm{K}+$ and lead to cell death. The 260$\mathrm{nm}$ absorbing material leakage is an index of irrecoverable damage to the membrane integrity in Eos groups compared to control. The nucleic acids which reside the interior of the cytoplasm are the vital controlling component of the cell systems. The present results showed that the exposure of bacterial species to Eos from Pogostemon species caused the rapid loss of 260-nm absorbing materials indicating an irreversible cytoplasmic membranes damage which was supported by the results of the $\mathrm{K}+$ permeability of cell membrane. The leakage of nucleic acids could cause the disorder of function in the synthesis of proteins and other materials and the inhibition of bacterial growth. Potassium levels influence multiphysiological events, including MP, acid-base homeostasis, fluid and electrolyte balance, glucose metabolism, and blood pressure control [23, 24]. Generally, the internal cell environment is rich in $\mathrm{K}+$, so their leaching in the extracellular medium is an indicator of disruption of cytoplasmic membrane damage. Therefore, abnormalities to the structural integrity of cell membrane can detrimentally affect cell metabolism and lead to cell death. Some Eos was recognized to have membrane active properties against several microorganisms, causing leakage of cell constituents, including ions [24, 25, 26, 27]. Thus, the overall results of the present study showed a remarkable increase in the leakage of ions. It indicated a disruption of the cell membrane and the disorder of 260 absorbing material balance of the bacterial cells which was consistent with the results of relative MIC, MKC and diameter of zone of inhibition. Further, the antibacterial effect may be also through derailment of proton motive force, regulating mitochondrial respiration, substrate oxidation, active transportation, and loss of pool biometabolites, as well as disruption of synthesis of macromolecules such as proteins, lipids and polysaccharides. In general, leakage of intracellular materials is induced by any antimicrobial agent results into the death of the cell [25]. The obtained activities may be attributed by the presence of several biologically active components present in the Eos of Pogostemon species.

\section{CONCLUSION}

In the present study, GC-MS analysis revealed $\alpha$-cadinol and patchouli alcohol as the major fractions in the essential oils of $P$. benghalensis and $P$. cablin respectively. The essential oils showed optimal microbicidal activity against the selected Gram positive bacteria, Gram negative bacterial and fungal strains. Further studies are warranted to identify which fractions of essential oils is responsible for the antimicrobial activity under in vitro and in vivo conditions. The results tempt to suggests that the both the essential oils act as potent antimicrobial agents and may be used in food and pharmaceutical industries.

\section{ACKNOWLEDGMENT}

Authors acknowledge the Director of JNTBGRI for providing facilities for the GC-MS analysis of Eos and herbaria reference for the proper identification of the species. 


\section{Indo Global Journal of Pharmaceutical Sciences, 2020; 10(3): 41-47}

\section{DATA AVAILABILITY}

Not declared.

\section{CONFLICTS OF INTEREST}

Nil

\section{FUNDING SOURCE}

No external funding declared.

\section{REFERENCES}

1. Franz, C.M. Essential oil research: Past, present and future. Flavour Frag. J., 2010; 25: 112-113.

2. Stefanakis, M.K., Touloupakis, E., Anastasopoulos, E., Ghanotakis, D., Katerinopoulos, H.E., Makridis, P. Antibacterial activity of essential oils from plants of the genus Origanum. Food Control. 2013; 34: 539-546.

3. Bakkali, F., Averbeck, S., Averbeck, D., Idaomar, M. Biological effects of essential oils - a review. Food Chem. Toxicol. 2008; 46: 446-475.

4. Gurib-Fakim, A. Medicinal plants: traditions of yesterday and drugs of tomorrow. Mol. Aspects. Med., 2006; 27: 1-93.

5. Valiakos, E., Marselos, M., Sakellaridis, N., Constantinidis, T., Skaltsa, H. Ethnopharmacological approach to the herbal medicines of the antidotes in Nikolaos Myrepsos' Dynameron. J. Ethnopharmacol., 2015; 163: 68-82.

6. Pandey, A.K., Mohan, M., Singh, P., Palni, U.T., Tripathi. N.N. Chemical composition, antibacterial and antioxidant activity of essential oil of Eupatorium adenophorum Spreng. from Eastern Uttar Pradesh. India. Food Biosci., 2014; 7: 80-88.

7. Tian, J., Zeng, X.B., Zhang, S. Regional variation in components and antioxidant and antifungal activities of Perilla frutescens essential oils in China. Ind. Crop. Prod., 2014; 59: 6979.

8. Harbottle, H., Thakur, S., Zhao, S., White, D.G. Genetics of antimicrobial resistance. Anim. Biotechnol., 2006; 17: 111-124.

9. Khan, A.U., Musharraf, A. Plasmid mediated multiple antibiotic resistances in Proteus mirabilis isolated from patients with urinary tract infection. Med. Sci. Mont., 2004; 10: 598- 602.

10. Obasohan, E.E., Agbonlahor, D.E., Obano, E.E. Water pollution: A review of microbial quality and health concerns of water, sediment and fish in the aquatic ecosystem. Afr. J. Biotech., 2010; 9(4): 423-427.

11. Das, P., Dutta, S., Begum, J., Nural, A.M. Antibacterial and antifungal activity analysis of essential oil of Pogostemon cablin (Blanco) Benth. Bangladesh J. Microbiol., 2013; 30(2): 07-10.

12. National Committee for Clinical Laboratory Standard (NCCLS). Performance standards for antimicrobial susceptibility testing, 9th International Supplement; M100-S9: Wayne; PA, USA, 1999.

13. Bajpai, V.K., Sharma, A., Baek, K.H. Antibacterial mode of action of Cudrania tricuspidata fruit essential oil, affecting membrane permeability and surface characteristics of foodborne pathogens. Food Control., 2013; 32: 582-90.

14. Carson, C.F., Mee, B.J., Riley, T.V. Mechanism of action of Melaleuca alternifolia (tea tree) oil on Staphylococcus aureus determined by time-kill, lysis, leakage, and salt tolerance assays and electron microscopy. Antimicrob. Agents. Chemother. 2002; 46: 1914-1920.

15. Zhan, Jzhou, P.A. A simplified method to evaluate the acute toxicity of ricin and ricius agglutinin. Toxicology., 2003; 186(12): $119-123$

16. Khare, C.P. Indian medicinal plants; Springer: New York, 2007.

17. Sartoratto, A., Machado, A., Delarmelina, C., Figueira, G., Duarte, M., Rehder, V. Composition and antimicrobial activity of essential oils from aromatic plants used in Brazil. Braz. J. Microbiol., 2004; 35(4): 275-280.

18. Adesokan, A., Akanji, M.A., Yakubu, M.T. Antibacterial potentials of aqueous extract of Enantia chlorantha stem bark. African J. Biotech., 2007; 6(22): 2502-2505.

19. Betoni J., Mantovani, R., Barbosa, L., Di Stasi, L.C. Synergiam between plant extract and antimicrobial drugs used on Staphylococcus aureus disease. . Mem. Inst. Oswaldo Cruz, Rio de Janerio., 2006; 101(4): 387-390.

20. Repentigny, Aumont, F., Bernard, K., Belhumeur, P. Characterization of binding of Candida albicans to small intestinal mucin and its role in adherence to mucosal epithelial cells. Infect. Immun., 2000; 68: 3172-3179.

21. Wang, G., Deng, J., Ma, Y., Shi, M., Li, B. Mechanisms, clinically curative effects, and antifungal activities of Cinnamon oil and Pogostemon oil complex against three species of Candida. J. Tradit. Chin. Med., 2012; 32(1): 1-2.

22. Burt, S. Essential oils: their antibacterial properties and potential applications in foods-a review. Int. J. Food Microbiol., 2004; 94: 223-253

23. Diao, W. R., Hu, Q.P., Zhang, H., Xu, J.G. Chemical composition, antibacterial activity and mechanism of action of essential oil from seeds of fennel (Foeniculum vulgare Mill.). Food Control., 2014; 35: 109-116.

24. Turgis, M., Han, J., Caillet, S., Lacroix, M. Antimicrobial activity of mustard essential oil against Escherichia coli O157:H7 and Salmonella typhi. Food Control., 2009; 20: 10731079.

25. Shukla, S., Majumder, R., Ahirwal, L., Mehta, A. Proposed mechanism of antibacterial mode of action of Caesalpinia bonducella seed oil against food-borne pathogens. Bangladesh J. Pharmacol., 2016; 11: 257-263.

26. Al-Reza, S.M., Rahman, A., Lee, J.H., Kang, S.C. Potential roles of essential oil and organic extracts of Zizyphus jujube in inhibiting food-borne pathogens. Food Chem., 2010; 119: 98186.

27. Rahman, A., Kang, S.C. In vitro control of food-borne and food spoilage bacteria by essential oil and ethanol extracts of Lonicera japonica Thunb. Food Chem., 2010; 116: 67-70.

Indo Global Journal of Pharmaceutical Sciences( ISSN 2249 1023; CODEN- IGJPAI; NLM ID: 101610675) indexed and abstracted in CrossRef (DOI Enabling), CNKI, UGC CARE Journal List, EMBASE (Elsevier), National Library of Medicine (NLM) Catalog (NCBI), ResearchGate, Publons (Clarivate Analytics), CAS (ACS), Index Copernicus, Google Scholar and many more. For further details, visit http://iglobaljournal.com 